\title{
Virtual Reality as an Embodied Tool to Enhance Episodic Memory in Elderly
}

\author{
Claudia Repetto $^{1 *}$, Silvia Serino ${ }^{1,2}$, Manuela Macedonia ${ }^{3,4}$ and Giuseppe Riva ${ }^{1,2}$ \\ ${ }^{1}$ Catholic University of the Sacred Heart, Department of Psychology, Milan, Italy, ${ }^{2}$ Istituto Auxologico Italiano, Applied \\ Technology for Neuro-Psychology Lab, Milan, Italy, ${ }^{3}$ Johannes Kepler University, Information Engineering, Linz, Austria, ${ }^{4}$ Max \\ Planck Institute for Human Cognitive and Brain Sciences, Leipzig, Germany
}

Keywords: embodied cognition, episodic memory, virtual reality, memory training, embodied memory

OPEN ACCESS

Edited by:

Annalisa Setti,

University College Cork, Ireland

Reviewed by:

Nadia Pantidi,

University College Cork, Ireland

*Correspondence:

Claudia Repetto claudia.repetto@unicatt.it

Specialty section:

This article was submitted to

Cognition,

a section of the journal

Frontiers in Psychology

Received: 14 June 2016 Accepted: 07 November 2016 Published: 17 November 2016

Citation:

Repetto C, Serino S, Macedonia M and Riva G (2016) Virtual Reality as an Embodied Tool to Enhance Episodic Memory in Elderly.

Front. Psychol. 7:1839. doi: 10.3389/fpsyg.2016.01839
In the last decade, embodiment has dramatically influenced our conception of cognition. In this new frame, episodic memory, and particularly memory decline have been reinterpreted. Interventions supporting memory in the aging population address the connection between mind and body. Here, we discuss the use of Virtual Reality (VR) as an innovative tool to support episodic memory in older adults.

\section{THE EMBODIED NATURE OF EPISODIC MEMORY AND ITS IMPLICATIONS FOR AGING}

Traditional cognitive models of human mind describe it as processing abstract symbols and following predefined formal rules (Fodor, 1975, 1983).

An alternative view, the embodied cognition approach, claims however that the mind is inherently embodied: this is to say that perceptual and motor systems influence the way we construct concepts, make inferences, and use language (Barsalou, 2008; Shapiro, 2011). Empirical evidence supports this claim in different cognitive domains: in language comprehension (Hauk et al., 2004; Tettamanti et al., 2005; Repetto et al., 2013, 2015b; Repetto, 2014), second language learning (Macedonia et al., 2011; Repetto et al., 2015a; Macedonia and Repetto, 2016), and also in memory (Pezzulo et al., 2010; van Dam et al., 2013; Downing-Doucet and Guérard, 2014; Bochynska and Laeng, 2015; Lagacé and Guérard, 2015). Specifically, it has been argued that the ability to encode and retrieve information is constrained by the actions we can perform upon it and by the limitations/opportunities provided by our bodies (Glenberg, 1997). The embodied nature of memory appears particularly evident for episodic memories. They consist of past events with reference to the individuals themselves as participants of those events (Tulving, 2001, 2002) and linked to a place and a particular time. According to Tulving (2001), the essence of episodic retrieval is the "autonoetic consciousness," namely the subjective and conscious experience of mentally reliving a personal past event. This includes "all the attendant visual, kinesthetic, and spatial impressions" (Wilson, 2002 p.633).

It has been argued that the ontogeny of episodic memory is strictly connected with the onset of locomotion during infancy, and related to the maturation of the hippocampus (Glenberg and Hayes, 2016). This brain structure, together with the entorhinal cortex, contains different kinds of cells dedicated to different tasks. Hippocampal place cells code location (Ekstrom et al., 2003). Head-direction cells provide a viewing direction on the retrieved contents (Taube, 1998) and allow the generation of an egocentrically coherent representation in medial parietal areas. Grid cells in the entorhinal cortex support the process of updating a viewpoint in relation to self-motion signals (Boccara et al., 2010). Glenberg and Hayes (2016) specifically proposed that the alignment of hippocampal place cells and grid cells related to environmental cues triggers the encoding of space in which personal events are experienced. Embodied navigation and memory are thus strictly connected (Leutgeb et al., 2005; Buzsáki and Moser, 2013). 
Miller et al. (2013) developed an hybrid memory test assessing both spatial and episodic memory for a group of epileptic patients implanted with depth electrodes. The test was implemented in a virtual reality environment. In the encoding phase, patients were asked to drive in a virtual city and to deliver different items to stores; in the retrieval phase, patients were prompted to verbally recall the items delivered during navigation. Miller and colleagues found that place cells that fired at a specific location during virtual navigation were also activated during subsequent recall of the item associated to that location. This indicates that activity was reinstated during retrieval in episodic memory.

The embodied approach of memory also accounts for the decline of episodic memory described during aging (Koen and Yonelinas, 2014). Here, the critical element is the reduction of locomotion observed in older individuals. The decrease of locomotion results in the reduction of the opportunities for the hippocampal place cells and grid cells to be tuned with the environment (Glenberg and Hayes, 2016). It stands to reason that, in order to enhance episodic memory in older adults, trainings procedures should target self-locomotion and navigation tasks. To this extent, Virtual Reality systems (VR) could be employed as training tool.

\section{VIRTUAL REALITY AS A TOOL TO IMPROVE EPISODIC MEMORY IN THE AGING POPULATION}

Virtual reality allows users to create, explore and interact within environments that are perceived as near to reality. Typically, users entering a VR lab feel as being a part of this world and behave as if they were in the real world (Riva and Mantovani, 2012; Riva et al., 2014). Specifically, even if users do not always move their bodies in the real space, users have the subjective perception of being "in action." The effect of a virtual action on cognitive processing has been demonstrated by Repetto et al. (2015b) who have found that performing a virtual movement with a limb (i.e., virtual run-performed with the legs/feet) speeds up the comprehension of verbs that describe actions performed with the same limb (to kick, performed with legs/feet). On this base, VR can be used to support episodic memory, in particular in elderly (Morganti et al., 2013).

Three main features that VR implements may have an impact on episodic memory in elderly:

First VR allows to experience from an egocentric point of view. This feature places VR in an intermediate position between mere action observation (such as in a video) and real action execution (Serino et al., 2015), with an important rebound on brain activity (Serino et al., 2014). In a fMRI study, Strafella and Paus (2000) have demonstrated that cortical excitability is modified by the observation of movements performed by others. Futhermore, this modulation can be enhanced if the orientation of the movement is egocentric (Maeda et al., 2002). In a recent experiment, Bergouignan et al. (2014) tested the egocentric point of view in relation to encoding and retrieving real-life events. Participants seating in front of a "professor" had a social interaction with him. They saw a real scene filmed and projected through a head-mounted display (HMD) connected to cameras in different locations. The first camera was located exactly over the participants' head, so that participants looked at the scene from the same perspective as without the HMDs. The second camera was located $2 \mathrm{~m}$ in front of the participants and rotated $180^{\circ}$ to face them. This experimental manipulation yielded two different subjective frames of reference. In the former, the sense of bodily self was located inside of the physical body (in-body condition). In the latter the sense of bodily self was located outside the physical body (out-of-body condition). To induce the illusion of being in one of these two locations, they received a visuo-tactile stimulation on their chest with a rod, synchronous with the scene projected to HMD. After a week, participants' episodic memory of these life events was assessed. Results revealed a poorer recollection for life events encoded in the out-of-body condition. Furthermore, findings indicated that the retrieval of these life events was associated with activity changes in the hippocampus. Considering these findings, VR allowing an egocentric encoding and retrieval, could be a valid training tool for episodic memory.

Second, VR allows active navigation while the user actively explores the environment by manipulating keyboards, joysticks, or controllers. Within a virtual world, the user can choose directions and get the impression of walking or running simply by regulating the motion speed. Being the self-locomotion the base of embodiment and grounding consequently episodic memory (Glenberg and Hayes, 2016) virtual promenades could compensate for the decrease of the spontaneous motion in elderly. Jebara et al. (2014) investigated the effect of different types of virtual navigation on episodic memory in young and older adults. In a virtual environment designed as a city to be explored from inside a car, participants were asked to retrieve the events occurred with questions on "what," "where," and "when." Participants were assigned to four experimental conditions: (1) in the passive condition participants were the passengers, with no possibility to interact with the environment; (2) in the itinerary control, participants chose the road but did not drive the car; (3) in the low navigation control, participants displayed the car on rails they could control with pedals without choosing the directions; (4) in the high navigation control, participants drove as in real life choosing also directions. As expected, the low navigation and the itinerary control conditions enhanced episodic memory in both young and older adults. A study by Sauzéon et al. (2016) report similar findings and suggest that active navigation in episodic memory by means of VR benefits memory. In this study, younger and older adults explored two versions ( $A$ and $B$ ) of a virtual apartment either actively by choosing directions or passively (through a computer-guided tour of the apartment). The participants were instructed to memorize all the objects located in the different rooms for future recall. Performance was measured with different memory tests. The results underlined that active navigation increased object recognition in both groups, but did not influence other memory tasks (free recall, proactive interference, and semantic clustering). The authors discussed this finding as analogy between active navigation and the enactment effect (Engelkamp et al., 1994). Thereafter recall and recognition of items of verbal items are 
enhanced if participants previously execute semantically related actions to the words. The similarity between active virtual navigation and enactment is given because both procedures selectively impact item-specific processing as recognition, but not relational processing (for example semantic clustering of concepts). Following this perspective, active navigation in VR, can tap into item-specific processing (Pedroli et al., 2015), known to be more defective in older adults compared to relational processing (Dennis et al., 2007). Third, VR provides environmental enrichment by using flexible scenarios. They can in turn be implemented with different degrees of complexity. From bi-dimensional (2D) to tri-dimensional perspectives (3D), the amount of spatial information can increase the degree of enrichment. A beneficial effect of environmental enrichment toward hippocampal function in mice (in terms of neurogenesis and hippocampus-dependent learning and memory tasks) has been reported by Kempermann et al. (1997). Specifically, it has been proven that VR place cells can be activated by means of virtual navigation (Harvey et al., 2009). In humans, Clemenson and Stark (2015) have demonstrated that 3D in virtual environments improves memory in tasks known to be related to hippocampal activity. In their study, the authors trained naïve video gamers for 2 weeks on two different videogames. One was based on simple $2 \mathrm{D}$ graphics, and one was based on $3 \mathrm{D}$ complex graphics. The control group received no training. Visual and memory performance were tested: visual accuracy and visual processing speed in an enumeration task, memory discrimination between highly similar lure items from repeated items, and a spatial memory score. Participants trained with the $3 \mathrm{D}$ videogame outperformed both, the $2 \mathrm{D}$ gamers and the control group in the discrimination task and in the spatial memory task, but not in the visual task. Being the discrimination task associated with the activity of the hippocampus (Lacy et al., 2010), authors inferred that 3D enriched VR presumably impacts

\section{REFERENCES}

Barsalou, L. W. (2008). Grounded Cognition. Ann. Rev. Psychol. 59, 617-645. doi: 10.1146/annurev.psych.59.103006.093639

Bergouignan, L., Nyberg, L., and Ehrsson, H. H. (2014). Out-of-body-induced hippocampal amnesia. Proc. Natl. Acad. Sci. U.S.A. 111, 4421-4426. doi: 10.1073/pnas.1318801111

Boccara, C. N., Sargolini, F., Thoresen, V. H., Solstad, T., Witter, M. P., Moser, E. I., et al. (2010). Grid cells in pre- and parasubiculum. Nat. Neurosci. 13, 987-994. doi: $10.1038 / \mathrm{nn} .2602$

Bochynska, A., and Laeng, B. (2015). Tracking down the path of memory: eye scanpaths facilitate retrieval of visuospatial information. Cogn. Process. 16, 159-163. doi: 10.1007/s10339-015-0690-0

Buzsáki, G., and Moser, E. I. (2013). Memory, navigation and theta rhythm in the hippocampal-entorhinal system. Nat. Neurosci. 16, 130-138. doi: 10.1038/nn.3304

Castilla, D., Garcia-Palacios, A., Bréton-López, J., Miralles, I., Baños, R. M., Farfallini, L., et al. (2013). Process of design and usability evaluation of a telepsychology web and virtual reality system for the elderly: Butler. Int. J. Hum. Comput. Stud. 71, 350-362. doi: 10.1016/j.ijhcs.2012.10.017

Clemenson, G. D., and Stark, C. E. (2015). Virtual environmental enrichment through video games improves hippocampal-associated memory. J. Neurosci. 35, 16116-16125. doi: 10.1523/JNEUROSCI.258015.2015 also the hippocampal activity. Taken together, these findings support the view that episodic memory can be enhanced in older adults by means of enriched 3D scenarios. They can stimulate hippocampal activity which in turn supports episodic memory.

However, the use of VR with elderly might have some limitations per se: the first affects the usability of different devices such as HMD, joypad or other controllers (Castilla et al., 2013). Elder persons are reluctant toward technology and not used to handle (Manera et al., 2016). The second limitation has to do with the cognitive load of the task. If the task is too demanding, this can have detrimental effects on the memory performance if attentional resources might split between complex motor tasks and memory task (Jebara et al., 2014).

Despite these caveats, these studies pave the way for a new concept of trainings for episodic memory: proposing VR as an effective tool for active navigation in $3 \mathrm{D}$ enriched worlds.

\section{AUTHOR CONTRIBUTIONS}

CR, GR conceived the paper. CR, SS wrote the paper. MM, GR revised the paper.

\section{ACKNOWLEDGMENTS}

This work was partially supported by the Italian funded project "High-End and Low-End Virtual Reality Systems for the Rehabilitation of Frailty in the Elderly" (PE-2013-02355948), by the research project Tecnologia Positiva e Healthy Aging (Positive Technology and Healthy Aging) (Grant D.3.2., 2014) and by the research project "Ageing and Healthy Living: A Human Centered Approach in Research and innovation as Source of Quality Life," funded by Fondazione Cariplo within the 2014.
Dennis, N. A., Hongkeun, K., and Cabeza, R. (2007). Effects of aging on true and false memory formation: an fmri study. Neuropsychologia 45, 3157-3166. doi: 10.1016/j.neuropsychologia.2007.07.003

Downing-Doucet, F., and Guérard, K. (2014). A motor similarity effect in object memory. Psychonomic Bull. Rev. 21, 1033-1040. doi: 10.3758/s13423-0130570-5

Ekstrom, A. D., Kahana, M. J., Caplan, J. B., Fields, T. A., Isham, E. A., Newman, E. L., et al. (2003). Cellular networks underlying human spatial navigation. Nature 425, 184-188. doi: 10.1038/nature01964

Engelkamp, J., Zimmer, H. D., Mohr, G., and Sellen, O. (1994). Memory of selfperformed tasks: self-performing during recognition. Mem. Cogn. 22, 34-39. doi: 10.3758/BF03202759

Fodor, J. A. (1975). The Language of Thought. Cambridge: Harvard University Press.

Fodor, J. A. (1983). The Modularity of Mind. Boston: MIT press.

Glenberg, A. M. (1997). What memory is for. Behav. Brain Sci. 20, 1-55.

Glenberg, A. M., and Hayes, J. (2016). Contribution of embodiment to solving the riddle of infantile amnesia. Front. Psychol. 7:10. doi: 10.3389/fpsyg.2016.00010

Harvey, C. D., Collman, F., Dombeck, D. A., and Tank, D. W. (2009). Intracellular dynamics of hippocampal place cells during virtual navigation. Nature 461, 941-946. doi: 10.1038/nature08499

Hauk, O., Johnsrude, I., and Pulvermüller, F. (2004). Somatotopic representation of action words in human motor and premotor cortex. Neuron 41, 301-307. doi: 10.1016/S0896-6273(03)00838-9 
Jebara, N., Orriols, E., Zaoui, M., Berthoz, A., and Piolino, P. (2014). Effects of enactment in episodic memory: a pilot virtual reality study with young and elderly adults. Front. Aging Neurosci. 6:338. doi: 10.3389/fnagi.2014. 00338

Kempermann, G., Kuhn, H. G., and Gage, F. H. (1997). More hippocampal neurons in adult mice living in an enriched environment. Nature 386, 493-495. doi: 10.1038/386493a0

Koen, J. D., and Yonelinas, A. P. (2014). The effects of healthy aging, amnestic mild cognitive impairment, and alzheimer's disease on recollection and familiarity: a meta-analytic review. Neuropsychol. Rev. 24, 332-354. doi: 10.1007/s11065014-9266-5

Lacy, J. W., Yassa, M. A., Stark, S. M., Muftuler, L. T., and Stark, C. E. L. (2010). Distinct pattern separation related transfer functions in human CA3/dentate and CA1 revealed using high-resolution fmri and variable mnemonic similarity. Learn. Mem. 18, 15-18. doi: 10.1101/lm.1971111

Lagacé, S., and Guérard, K. (2015). when motor congruency modulates immediate memory for objects. Acta Psychol. 157, 65-73. doi: 10.1016/j.actpsy.2015.02.009

Leutgeb, S., Leutgeb, J. K., Moser, M. B., and Moser, E. I. (2005). Place cells, spatial maps and the population code for memory. Curr. Opin. Neurobiol. 15, 738-746. doi: 10.1016/j.conb.2005.10.002

Macedonia, M., Müller, K., and Friederici, A. D. (2011). The impact of iconic gestures on foreign language word learning and its neural substrate. Hum. Brain Mapp. 32, 982-998. doi: 10.1002/hbm.21084

Macedonia, M., and Repetto, C. (2016). Brief multisensory training enhances second language vocabulary acquisition in both high and low performers. Int. J. Learn. Teach. Edu. Res. 15, 42-53.

Maeda, F., Kleiner-Fisman, G., and Pascual-Leone, A. (2002). Motor facilitation while observing hand actions: specificity of the effect and role of observer's orientation. J. Neurophysiol. 87, 1329-1335. doi: 10.1152/jn.00773.2000

Manera, V., Chapoulie, E., Bourgeois, J., Guerchouche, R., David, R., Ondrej, J., et al. (2016). A feasibility study with image-based rendered virtual reality in patients with mild cognitive impairment and dementia. PLOS ONE 11:e0151487. doi: 10.1371/journal.pone.0151487

Miller, J. F., Neufang, M., Solway, A., Brandt, A., Trippel, M., Mader, I., et al. (2013), Neural activity in human hippocampal formation reveals the spatial context of retrieved memories. Science 342, 1111-1114. doi: 10.1126/science. 12 44056

Morganti, F., Stefanini, S., and Riva, G. (2013). From allo-to egocentric spatial ability in early Alzheimer's disease: a study with virtual reality spatial tasks. Cogn. Neurosci. 4, 171-180. doi: 10.1080/17588928.2013.85476

Pedroli, E., Serino, S., Cipresso, P., Pallavicini, F., and Riva, G. (2015). Assessment and rehabilitation of neglect using virtual reality: a systematic review. Front. Behav. Neurosci. 9:226. doi: 10.3389/fnbeh.2015.00226

Pezzulo, G., Barca, L., Bocconi, A. L., and Borghi, A. M. (2010). When affordances climb into your mind: advantages of motor simulation in a memory task performed by novice and expert rock climbers. Brain Cogn. 73, 68-73. doi: 10.1016/j.bandc.2010.03.002

Repetto, C. (2014). The use of virtual reality for language investigation and Learning. Front. Psychol. 5:1280. doi: 10.3389/fpsyg.2014.01280

Repetto, C., Colombo, B., Cipresso, P., and Riva, G. (2013). The effects of rTMS over the primary motor cortex: the link between action and language. Neuropsychologia 51, 8-13. doi: 10.1016/j.neuropsychologia.2012. 11.001

Repetto, C., Colombo, B., and Riva, G. (2015a). Is motor simulation involved during foreign language learning? A virtual reality experiment. SAGE Open 5. doi: $10.1177 / 2158244015609964$
Repetto, C., Cipresso, P., and Riva, G. (2015b). Virtual action and real action have different impacts on comprehension of concrete verbs. Front. Psychol. 6:176. doi: $10.3389 /$ fpsyg.2015.00176

Riva, G., and Mantovani, F. (2012). From the body to the tools and back: a general framework for presence in mediated interactions. Interact. Comput. 24, 203-210. doi: 10.1016/j.intcom.2012.04.007

Riva, G., Waterworth, J., and Murray, D. (eds.). (2014). Interacting with Presence: HCI and the Sense of Presence in Computer-mediated Environments. Berlin: Walter de Gruyter GmbH \& Co KG.

Sauzéon, H., N'Kaoua, B., Arvind Pala, P., Taillade, M., and Guitton, P. (2016). Age and active navigation effects on episodic memory: a virtual reality study. $\mathrm{Br}$. J. Psychol. 107, 72-94. doi: 10.1111/bjop.12123

Serino, S., Cipresso, P., Morganti, F., and Riva, G. (2014). The role of egocentric and allocentric abilities in Alzheimer's disease: a systematic review. Ageing Res. Rev. 16, 32-44. doi: 10.1016/j.arr.2014.04.004

Serino, S., Morganti, F., Di Stefano, F., and Riva, G. (2015). Detecting early egocentric and allocentric impairments deficits in Alzheimer's disease: an experimental study with virtual reality. Front. Aging Neurosci. 7:88. doi: 10.3389/fnagi.2015.00088

Shapiro, L. A. (2011). Embodied Cognition. New York: NY: Routledge.

Strafella, A. P., and Paus, T. (2000). Modulation of cortical excitability during action observation: a transcranial magnetic stimulation study. Neuroreport 11, 2289-2292.

Taube, J. S. (1998). Head direction cells and the neurophysiological basis for a sense of direction. Prog. in Neurobiol. 55, 225-256. doi: 10.1016/S03010082(98)00004-5

Tettamanti, M., Buccino, G., Saccuman, M. C., Gallese, V., Danna, M., Scifo, P., et al. (2005). Listening to action-related sentences activates fronto-parietal motor circuits. J. Cogn. Neurosci. 17, 273-281. doi: 10.1162/08989290531 24965

Tulving, E. (2001). Episodic memory and common sense: how far apart?" Philos. Trans. R. Soc. Lond. B Biol. Sci. 356, 1505-1515. doi: 10.1098/rstb. 2001.0937

Tulving, E. (2002). Episodic memory: from mind to brain. Ann. Rev. Psychol. 53, 1-25. doi: 10.1146/annurev.psych.53.100901.135114

van Dam, W. O., Rueschemeyer, S. A., Bekkering, H., Lindemann, O. (2013). Embodied grounding of memory: toward the effects of motor execution on memory consolidation. Q. J. Exp. Psychol. 66, 2310-2328. doi: 10.1080/17470218.2013.777084

Wilson, M. (2002). Six views of embodied cognition. Psychonomic Bull. Rev. 9, 625-636. doi: 10.3758/BF03196322

Conflict of Interest Statement: The authors declare that the research was conducted in the absence of any commercial or financial relationships that could be construed as a potential conflict of interest.

The reviewer NP and the handling Editor declared their shared affiliation, and the handling Editor states that the process nevertheless met the standards of a fair and objective review.

Copyright (C) 2016 Repetto, Serino, Macedonia and Riva. This is an open-access article distributed under the terms of the Creative Commons Attribution License (CC $B Y)$. The use, distribution or reproduction in other forums is permitted, provided the original author(s) or licensor are credited and that the original publication in this journal is cited, in accordance with accepted academic practice. No use, distribution or reproduction is permitted which does not comply with these terms. 